\title{
The contribution of tyre-evolution to the reduction of soil compaction risks
}

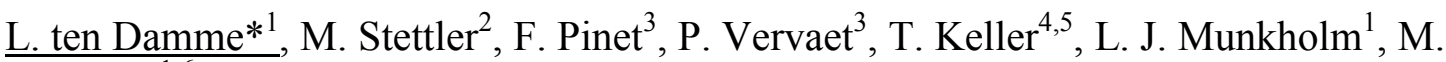
Lamandé , $^{1,6}$

${ }^{1}$ Faculty of Agricultural Sciences, Department of Agroecology and Environment, University of Aarhus, Research Centre Foulum, P.O. Box 50, DK-8830 Tjele, Denmark

${ }^{2}$ Bern University of Applied Sciences, School of Agricultural, Forest and Food Sciences HAFL, Länggasse 85, CH-3052 Zollikofen, Switzerland

${ }^{3}$ Michelin Ladoux, rue Bleue - ZI de Ladoux, 63118 Cebazat, France

${ }^{4}$ Agroscope, Department of Agroecology \& Environment, Reckenholzstrasse 191, CH-8046 Zürich, Switzerland

${ }^{5}$ Swedish University of Agricultural Sciences, Department of Soil \& Environment, P.O. Box 7014, SE-75007, Uppsala, Sweden

${ }^{6}$ Norwegian University of Life Sciences, Faculty of Environmental Sciences and Natural Resource Management, Campus As, Universitetstunet 3, 1430 As, Norway

* corresponding author: 1td@agro.au.dk

The use of today's heavy machinery in agriculture brings a great risk of soil degradation by compaction. Subsoil compaction persist for decades, thus reduction of the risk of subsoil compaction is extremely important. The risk of compaction is governed by the soil capacity to resist stress (soil strength) and by the stress induced by a vehicle. The stress distribution in the contact area between the tyre and the soil is of primary importance for the stresses propagating in the soil. Hence, tyre characteristics affect soil stress and the risk of compaction. Tyre manufacturers develop new technologies and designs to respond to the increasing concerns for soil deformation during traffic. However, no objective evaluation of tyre evolution to the protection of soil structure has been performed yet. The objective of this study was to compare effects of five tractor tyres introduced between 1970's and 2017 on soil stress and soil structure. Contact stress distribution was estimated using the FRIDA model. Soil stress propagation and soil physical properties were quantified in a field experiment on a clay soil in Clermont-Ferrand, France in March 2018. A wheel load of 4,300 kg was chosen for all five tyres and the load-rated inflation pressures ranged from $0.6-2.4$ bar. Bolling probes were installed to determine the mean normal stress at three depths $(20,40$, and $60 \mathrm{~cm})$ beneath the centre and at $30 \mathrm{~cm}$ outside of the centre, at the edge of the three newest tyres. Soil physical properties before and after one pass of each of the five tyres were measured on undisturbed soil cores $\left(100 \mathrm{~cm}^{3}\right)$ sampled at $30 \mathrm{~cm}$. Preliminary results of stress measurements showed a lowest mean normal stress at all depths with newer tyres, both below the centre of the tyre as at the edge, even though the effect decreased with increasing depth. Air permeability at $30 \mathrm{~cm}$ depth showed no significant effect (P-value 0.068 at $5 \%$ significance level), but was low for all treatments and characterized by a narrow range. These preliminary results indicate that tyre design can play an important role in reducing soil stress for a given wheel load. Tyre design might then also help reducing the compaction risk for larger wheel loads and other soil conditions than tested in the present study. 